OPEN ACCESS

Edited by:

Maria F. Drincovich,

CONICET Center for Photosynthetic and Biochemical Studies

(CEFOBI), Argentina

Reviewed by:

Benedetto Ruperti,

University of Padova, Italy

Christopher B. Watkins,

Cornell University, United States

*Correspondence: Athanassios Molassiotis amolasio@agro.auth.gr

Specialty section: This article was submitted to

Plant Abiotic Stress,

a section of the journal

Frontiers in Plant Science

Received: 01 October 2019

Accepted: 07 January 2020

Published: 13 February 2020

Citation:

Karagiannis E, Tanou G, Scossa F,

Samiotaki M, Michailidis $M$,

Manioudaki M, Laurens F, Job D, Fernie AR, Orsel $M$ and Molassiotis A (2020) Systems-Based Approaches to

Unravel Networks and Individual

Elements Involved in Apple Superficial Scald.

Front. Plant Sci. 11:8.

doi: 10.3389/fpls.2020.00008

\title{
Systems-Based Approaches to Unravel Networks and Individual Elements Involved in Apple Superficial Scald
}

\begin{abstract}
Evangelos Karagiannis ${ }^{1}$, Georgia Tanou ${ }^{2}$, Federico Scossa ${ }^{3,4}$, Martina Samiotaki ${ }^{5}$, Michail Michailidis ${ }^{1}$, Maria Manioudaki ${ }^{1}$, François Laurens ${ }^{6}$, Dominique $\mathrm{Job}^{7}$, Alisdair R. Fernie ${ }^{3}$, Mathilde Orsel $^{6}$ and Athanassios Molassiotis ${ }^{1 *}$

${ }^{1}$ Laboratory of Pomology, Department of Agriculture, Aristotle University of Thessaloniki, Thessaloniki, Greece, ${ }^{2}$ Institute of Soil and Water Resources, ELGO-DEMETER, Thessaloniki, Greece, ${ }^{3}$ Department Willmitzer, Max-Planck-Institute of Molecular Plant Physiology, Potsdam-Golm, Germany, ${ }^{4}$ Council for Agricultural Research and Economics, Research Center for Genomics and Bioinformatics, Rome, Italy, ${ }^{5}$ Institute for Bioinnovation, Biomedical Sciences Research Center "Alexander Fleming", Vari, Greece, 6 Institut de Recherche en Horticulture et Semences (IRHS), UMR 1345, INRA, Agrocampus-Ouest, Université d'Angers, Beaucouzé, France, ${ }^{7}$ Centre National de la Recherche Scientifique - Université Claude Bernard Lyon 1 - Institut National des Sciences Appliquées-Bayer CropScience, Lyon, France
\end{abstract}

Superficial scald is a major physiological disorder in apple fruit that is induced by cold storage and is mainly expressed as brown necrotic patches on peel tissue. However, a global view of the gene-protein-metabolite interactome underlying scald prevention/ sensitivity is currently missing. Herein, we have found for the first time that cold storage in an atmosphere enriched with ozone $\left(\mathrm{O}_{3}\right)$ induced scald symptoms in 'Granny Smith' apple fruits during subsequent ripening at room temperature. In contrast, treatment with the ethylene perception inhibitor 1-methylcyclopropene (1-MCP) reversed this $\mathrm{O}_{3}$-induced scald effect. Amino acids, including branched-chain amino acids, were the most strongly induced metabolites in peel tissue of 1-MCP treated fruits. Proteins involved in oxidative stress and protein trafficking were differentially accumulated prior to and during scald development. Genes involved in photosynthesis, flavonoid biosynthesis and ethylene signaling displayed significant alterations in response to 1-MCP and $\mathrm{O}_{3}$. Analysis of regulatory module networks identified putative transcription factors (TFs) that could be involved in scald. Subsequently, a transcriptional network of the genes-proteinsmetabolites and the connected TFs was constructed. This approach enabled identification of several genes coregulated by TFs, notably encoding glutathione $S$ transferase (GST) protein(s) with distinct signatures following 1-MCP and $\mathrm{O}_{3}$ treatments. Overall, this study is an important contribution to future functional studies and breeding programs for this fruit, aiding to the development of improved apple cultivars to superficial scald.

Keywords: apple fruit, ethylene inhibition, glutathione $S$-transferases, metabolites, ozone, proteomics, ripening, superficial scald 


\section{INTRODUCTION}

Apple (Malus $\times$ domestica Borkh.) is one of the most marketable and popular fruit crops; over $80 \mathrm{Mt}$ are produced per year throughout the temperate regions of the world (FAO statistic, http://faostat3.fao.org). Cold storage of susceptible apple cultivars is widely used to delay apple fruit ripening and senescence programs (Zermiani et al., 2015). However, the long-term cold storage of apples leads to development of superficial scald, a major physiological disorder that is characterized by necrosis of the hypodermal cortical tissue. These symptoms could be developed during cold storage and become more evident during subsequent ripening at room temperature, thus reducing the market quality of susceptible apple cultivars, such as 'Granny Smith' (Lurie and Watkins, 2012).

The complex regulation of scald is one of the most important topics in fruit research, but this phenomenon is still unclear (Storch et al., 2017). Early studies linked the oxidation of $\alpha$ farnesene, a natural volatile compound present in the wax of the fruit, and its oxidation into conjugated trienols (CTols) and ketone 6-methyl-5-hepten-2-one (MHO) during scald development (Rowan et al., 1995). Currently, this $\alpha$-farnesene theory has been debated, and it has been suggested that several other pathways could directly or indirectly be involved in scald disorder. It has been recently proposed that cold-induced oxidative stress in the peel of 'Granny Smith' are linked to the accumulation of chlorogenic acid in the vacuole, which in turn could react with polyphenol oxidase (PPO), leading to the peel browning that is typical of scald (Busatto et al., 2018). Further, inhibition of ethylene perception by 1-MCP has been shown to stimulate the production of antioxidant compounds to scavenge reactive oxygen species (ROS), the synthesis of fatty acids to stabilize plastid and vacuole membranes against cold, and the accumulation of sorbitol that can act as a cryoprotectant (Busatto et al., 2018).

High-throughput biological approaches like transcriptomics, proteomics, and metabolomics have been widely used to explore low temperature storage-responsive mechanisms in fruits (Molassiotis et al., 2013). Analyses from omics perspectives of apple scald have been conducted, including RNAseq (Busatto et al., 2018), proteomics (Du et al., 2017) and metabolomics (Rudell et al., 2009; Busatto et al., 2014; Gapper et al., 2017). Despite such progress, combination analyses of these different omics approaches and of the corresponding data sets by network construction and characterization of regulatory pathways in relation to scald have not yet been reported.

In the present work, we aimed to characterize scald responses in apple fruit, to uncover the metabolic relationships between scald-affected and healthy phenotypes, and thus we applied to 'Granny Smith' apples individual and combined treatments with the 1-methylcyclopropene (1-MCP), an inhibitor of ethylene perception, as well as with ozone $\left(\mathrm{O}_{3}\right)$, which is a powerful oxidant compound known to inhibit ethylene biosynthesis in kiwifruit (Minas et al., 2014; Minas et al., 2018). We revealed, for the first time, that ozone induced scald symptoms while 1-MCP totally reversed this $\mathrm{O}_{3}$-stimulated scald effect. By using this novel experimental system and by employing a multiomics approach and regulatory module networks analysis we identified pathways and networks as well individual elements (putative transcription factors/genes/proteins/metabolites) involved in scald prevention/sensitivity.

\section{MATERIALS AND METHODS}

\section{Experimental Design and Treatments}

'Granny Smith' apple fruits were harvested at physiologically mature stage (firmness: $7.59 \mathrm{~kg} \pm 0.12 \mathrm{~kg}$; soluble solids content: $11.8 \% \pm 0.1 \%$, titratable acidity (malic acid, $\%$ ): $0.77 \% \pm 0.02 \%$; dry weight: $14.03 \% \pm 0.02 \%$ ) from a commercial orchard at Imathia region (North Greece). Fruits were randomly divided into two groups of 250 fruits each. Apples of the first group were treated with 1-MCP $\left(1 \mu \mathrm{l} \mathrm{L}{ }^{-1}\right.$, SmartFresh, AgroFresh Inc., Rohm and Haas, Spring House, USA) for $24 \mathrm{~h}$ at $0^{\circ} \mathrm{C}$, according to manufacturer's instructions, whereas the second group remained untreated (control). Fruits from each group were cold stored $\left(0^{\circ}\right.$ C, $95 \% \mathrm{RH}$ ) in two separated cold rooms in the absence or presence of enriched $\mathrm{O}_{3}$ atmosphere $\left(0.3 \mu \mathrm{L} \mathrm{L}^{-1}\right)$ through a dedicated system of continuous $\mathrm{O}_{3}$ generation and monitoring (ozone generator model COM-AD-04 and ozone analyser model MP-6060, Anseros Klaus Nonnenmacher GmbH, Tübingen, Germany) for 6 months. Following cold storage, fruits from the four different treatments (control, 1-MCP, $\mathrm{O}_{3}, 1-\mathrm{MCP}+\mathrm{O}_{3}$ ) were analyzed for the development of scald symptoms after 0,1 , 3 , and 5 days (d) ripening at room temperature $\left(20^{\circ} \mathrm{C}\right)$. Each analysis at room temperature immediately after the cold storage ( $0 \mathrm{~d}$ at room temperature) compared to harvest time was named "cold storage effect." Sampling at postcold ripening period and before scald visual appearance ( $0 \mathrm{~d}$ at room temperature) was defined as "presymptomatic period," while sampling after $5 \mathrm{~d}$ ripening in which all scald-affected fruits (Figure 1A) was defined as "symptomatic period." For each treatment, three replicates of the whole peel tissue per fruit were isolated from seven apples, and subsequently frozen in liquid nitrogen and stored at $-80^{\circ} \mathrm{C}$ for further analysis.

\section{Physiological and Statistical Analyses of Apple Ripening}

Fruit firmness, soluble solids concentration (SSC), titratable acidity (TA, malic acid \%) and respiration rate were measured according to Karagiannis et al. (2018a). Statistical analysis was conducted using SPSS 20.0 (SPSS, Chicago, IL, USA). The means of three independent biological replications of seven fruits per replication were used for firmness, SSC and TA analysis, while three independent biological replications of two fruits per replication were used for respiration rate and ethylene determination. Subsequently, data were subjected to analysis of variance and least significant differences (LSD with SEM) at 5\% level were used for means comparison.

\section{Evaluation of Superficial Scald Symptoms}

The percent of scald surface was recorded as incidence and severity of affected fruits using a scale where $0=$ none, $1=1 \%$ - 


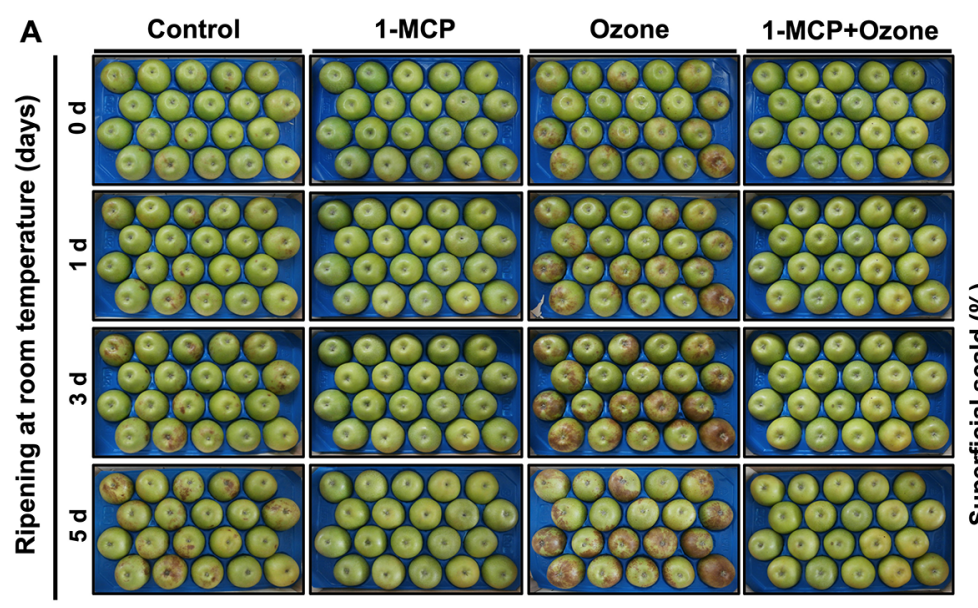

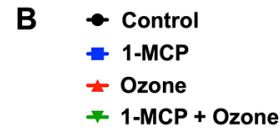
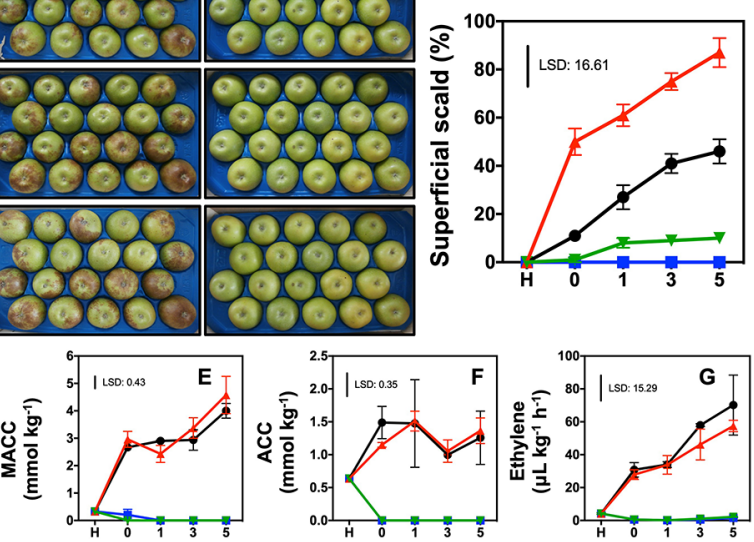

FIGURE 1 | Regulation of scald development and ethylene metabolism in response to chemical treatments. Apples (cv. Granny Smith) were treated or not with 1$\operatorname{MCP}\left(1 \mu \mathrm{L}^{-1}\right)$ and cold stored $\left(0^{\circ} \mathrm{C}\right)$ for 6 months in the presence or absence of $\mathrm{O}_{3}$ atmosphere $\left(0.3 \mu \mathrm{L} \mathrm{L}^{-1}\right)$. Subsequently the fruits were transferred at room temperature to characterize their ripening and scald development for up to 5 days. Phenotypes of apple fruits picturing different expression of scald syndrome (A), percentage of apple's peel affected by superficial scald (B), changes in enzymatic activities of ACC synthase (ACS) (C) and ACC oxidase (ACO) (D) as well as steady-state level of 1-malonyl-aminocyclo-propane-1-carboxylic acid (MACC) (E) and 1-aminocyclopropane-1-carboxylic acid ACC (F), and ethylene concentration (G). The vertical bar represents the least significant difference (LSD, P $=0.05$ ) of three independent biological replications, which was used for means comparison between the different treatments and time points, while the vertical bars at each time point represent the standard error of the means (SEM).

$10 \%, 2=11 \%-33 \%, 3=34 \%-66 \%$, and $4=67 \%-100 \%$ of the surface area (Karagiannis et al., 2018b). Statistical analysis was performed as described above (three independent biological replications of thirty fruits per replication).

\section{Analysis of Basic Metabolites and Enzymes of Ethylene Biosynthesis (Yang Cycle)}

Ethylene production was measured using a gas chromatograph system (GC-2014ATF Shimadzu) (Tanou et al., 2017). Enzymes and metabolites of the ethylene biosynthesis cycle were determined at grinded tissue and extracted as previously described by Bulens et al. (2011). Statistical analysis was performed as described above (three independent biological replications of seven fruits per replication).

\section{Metabolic Profiling by GC-ToF-MS Analysis}

Primary metabolites, collected at commercial harvest point as well as at 0 and $5 \mathrm{~d}$ of ripening, were extracted and derivatized from $250 \mathrm{mg}$ of freeze dried peel tissue and analyzed using a gas chromatography time of flight-mass spectrometry (GC-ToF-MS) according to established procedures (Lombardo et al., 2011). Peaks were identified using Tagfinder (Luedemann et al., 2008) and their identity confirmed using the mass spectral tags in the MPI-MP Golm database (Hummel et al., 2010). Metabolite relative amounts were normalized on the peak area of the internal standard ribitol according to the procedure outlined in Roessner et al. (2000). The normalized values of the 46 primary metabolites were also analyzed by one-way ANOVA followed by Duncan's test to detect significant differences $(\mathrm{P}<0.05)$. Further details regarding the protocols for metabolic profiling and the full data set of identified metabolites are reported in Supplementary Table 1 following established guidelines (Fernie et al., 2011). Mean values of five independent samples for each stage were expressed as the log2-transformed ratio between each treatment compared to control at different stage (Figure 2).

\section{Quantitative Proteome Analysis}

At the same time points sampled for metabolomic analysis, peel tissue $(5 \mathrm{~g})$ were used for protein extraction based on phenol extraction protocol at total volume of $12 \mathrm{ml}$ (Karagiannis et al., 2016). Two-dimensional electrophoresis was performed according to Tanou et al. (2010) using a BIO-RAD system. Following silver nitrate staining (Minas et al., 2016), 2DE-gels were scanned with Bio-Rad GS-800 Calibrated Densitometer equipped with PDQuest Advanced 2-DE Gel Analysis Software (Supplementary Figure 2). Statistical analysis of three independent biological replications was done by one-way analysis of variance significance $(P \leq 0.05)$ and individual means were compared using Student's t-test $(P \leq 0.05)$. In 


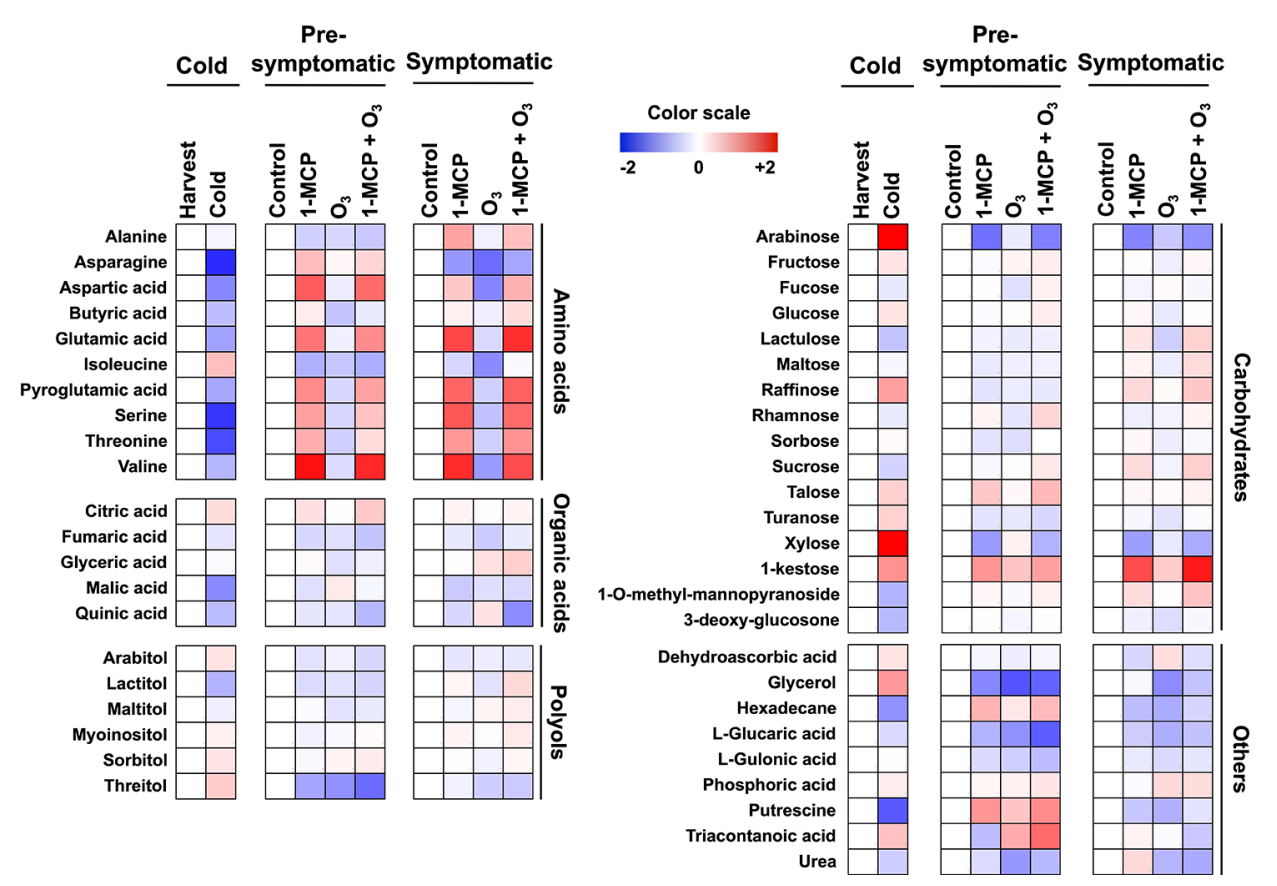

FIGURE 2 | Modulation of apple peel metabolites following 1-MCP and $\mathrm{O}_{3}$ treatments. Changes in primary metabolites in peel tissue exposed to 1-MCP and $\mathrm{O}_{3}$ at "cold", "presymptomatic", and "symptomatic" period. Treatments and sampling were performed as described in Figure $\mathbf{1}$ and under "Materials and Methods." A color scale that is proportional to the log2 ratio of each identified metabolite shows the fold change between treated and control fruits. Mean values of three independent measurements for each treatment were analyzed between the treatments and the control. Relative values for each metabolite mean are provided in Supplementary Table 1.

addition to the $\mathrm{p}$ value criterion, spots showing an at least 2.5 fold change of volume were considered as statistically significant (Tanou et al., 2015).

Spots of interest underwent tryptic in-gel digestion and peptide fragments analyzed by MALDI-MS in a TOF-MS (Ultraflex II, Bruker Daltonics, Bremen, Germany) as detailed by Tanou et al. (2017). Peptide mixtures were analyzed in a MALDI-TOF mass spectrometer (Autoflex-Speed, Bruker Daltonics). Raw files were searched against the Uniprot Malus domestica protein database using the (MASCOT Server v2.0). The mass error tolerance on the Mascot server was set to $25 \mu \mathrm{L}^{-1}$ methionine oxidation was considered as a variable modification and cysteine carbamidomethylation was considered as a fixed modification. All peptide sequences, accession numbers, Mascot scores and sequence coverage are provided in Supplementary Table 4. For nonidentified spots, peptide fragments were analyzed by LC-MS/MS using a LTQ Orbitrap XL Mass spectrometer (Thermo Fisher Scientific, Bremen, Germany) coupled online with a nanoLC Ultimate 3000 chromatography system (Dionex, Sunnyvale, CA) (Ainalidou et al., 2016). Raw files were searched against the ncbi Malus domestica protein database using PD 1.4 and the SEQUEST HT search engine. Protein identification required minimal XCorr values of 2.0, and 2.5 for charge states of doubly, and triply precursor ions respectively (Supplementary Table 4). Where protein annotations were missing, manual protein BLAST was performed against the current databases. Identifications are based on at least two peptides per protein. When presented, identifications based on single peptide additional information are provided (Supplementary Table 5). This work is MIAPE compliant. The mass spectrometry proteomics data have been deposited to the ProteomeXchange Consortium via the PRIDE [1] partner repository with the dataset identifier PXD016849.

\section{RNA Extraction, Amplification, and Hybridization}

Total RNA was extracted from $1 \mathrm{~g}$ of grinded frozen fruit peel tissue plus $5 \mathrm{ml}$ of extraction buffer, as described (Nobile et al., 2011; Segonne et al., 2014). Total mRNAs were amplified, labelled and cohybridized according to Celton et al. (2014) as follows: amplified aRNAs were produced with Message AmpII aRNA amplification kit (Ambion) from $200 \mathrm{ng}$ of total RNA. Then, each aRNA $(5 \mu \mathrm{g})$ was retrotranscribed and labelled with either Cyanine-3 or Cyanine-5 fluorescent dye (Interchim, Montluçon, France). Labelled samples were combined as 30 pmol for each dye and cohybridized to the Agilent microarray AryANE v2.0 (GPL26715) containing 135,000 60-mers oligonucleotide probes as described (Daccord et al., 2017). The experimental design included four comparisons with respectively 1-MCP, $\mathrm{O}_{3}, 1-\mathrm{MCP}+\mathrm{O}_{3}$ treated fruits versus control fruits and 1$\mathrm{MCP}+\mathrm{O}_{3}$ treated fruits versus $\mathrm{O}_{3}$ treated fruits, all at presymptomatic/prosymptomatic stage after 6 months of cold 
storage. Each comparisons included two sampling repetitions using the dye switch statistical technique according to (MaryHuard et al., 2008).

\section{Microarray Analysis}

The Agilent Feature Extraction 11.5 software was used to extract data files from from the scanned images obtained using the MS200 microarray scanner (Roche Nimblegen). All statistical analyses were conducted based on a dye switch approach as described (Daccord et al., 2017) with the $\mathrm{R}$ software ( $\mathrm{R}$ development Core Team, 2009). Briefly, data were normalized with the Lowess's method, and differential expression analyses were carried out using the lmFit function and the Bayes moderated $t$ test using the $\mathrm{R}$ package LIMMA (Smyth, 2005) from the Bioconductor project. Genes were considered differentially expressed if the t-test $P$-values of the paired sample were below $1 \%$. Genesis software was used to visualize results. Functional classification was based on Mapman ontology (Usadel et al., 2005; Zhao et al., 2019). Microarray data have been submitted to the Gene Expression Omnibus under the accession number GPL26715. Both antisense (AS) and sense (S) probes were designed for each sample, and $16.5 \%$ of the significantly expressed probes corresponded to antisense (AS) transcripts (Supplementary Table 5). Previous studies (Dheilly et al., 2016) demonstrated that AS transcripts were likely to be involved in small interfering RNA (siRNA), dependent on the negative regulation of the coding mRNAs. Subsequently, this current study considers only the genes with sense (S) probes as differentially expressed transcripts.

\section{Gene Expression Quantification by RT-qPCR}

The RNA samples used for the microarrays experiments were treated with $2 \mathrm{U}$ of DNAse I (Promega, USA) and cDNAs were synthesized from $1 \mu \mathrm{g}$ of DNA-free-RNA with oligo(dT) 15 and $200 \mathrm{U}$ of MMLV-RT (Promega) according to Segonne et al. (2014). For each cDNA, qPCR experiments were carried out according to Segonne et al. (2014) and Dheilly et al. (2016). Based on microarray results, seven genes of interest (GOI) were selected for being differentially expressed in two or more comparisons, while five genes were selected for never being differentialy expressed in all four comparisons to be used as reference genes (Celton et al., 2014; Vergne et al., 2014; Dheilly et al., 2016). Primer pairs for selected genes (Supplementary Table 6) were tested for their respective specificity and efficiency using a dilution curve method. Only primer pairs with efficiencies higher than $85 \%$ were retained for further analysis. Relative expression levels of three independent biological replicates were calculated according to Livak and Schmittgen (2001).

\section{Network Analysis}

Transcriptional regulatory networks including modules and regulatory interactions were inferred among transcripts, proteins and metabolites, using the probabilistic module networks frameworks LeMoNe that uses ensemble based probabilistic optimization techniques to identify clusters of coexpressed transcripts as well as their regulators (Espley et al., 2007). Data set used for the network analysis were the log2 ratio from the list of the differentially regulated genes selected by the 1-MCP, $\mathrm{O}_{3}$ and 1-MCP $+\mathrm{O}_{3}$ comparisons to treatment, as well as the proteins and the metabolites listed in Supplemental Tables $\mathbf{1}, \mathbf{3}$, and 5, respectively. Annotations for transcription factors were downloaded from the Transcription Factor Database (http://planttfdb.cbi.pku.edu.cn).

\section{RESULTS}

\section{Superficial Scald Symptoms Development}

Phenotypic (Figure 1A; the same fruits are presented at different time points) and scald evaluation (Figure 1B) indicated that control and especially ozone-treated fruits (without 1-MCP exposure) exhibited scald symptoms at $0 \mathrm{~d}$ ripening. At day 5, approximately $87 \% \mathrm{O}_{3}$-treated apples developed scald symptoms while control fruits showed about $46.0 \%$ scald (Figure 1B). Nevertheless, 1-MCP-treated apples, in the presence or in the absence of $\mathrm{O}_{3}$, substantially reduced scald injury (10\%). Scald symptoms were low (9.5\%) in fruit exposed to combined 1-MCP and $\mathrm{O}_{3}$ application (1-MCP+O $\mathrm{O}_{3}$ treatment) while no scald was detected in fruit treated with 1-MCP (Figure 1B).

\section{Effect of 1-MCP and $\mathrm{O}_{3}$ on Apple Climacteric Ripening}

Treatment with 1-MCP inhibited ethylene biosynthesis (Figures 1C-G). In contrast, activities of ACS and ACO, and ACC and MACC levels along with ethylene production (Figures 1C-G) remained unaffected in $\mathrm{O}_{3}$-treated apples compared to control (Supplementary Figure 1).

\section{Metabolic Profiling in 1-MCP and $\mathrm{O}_{3}-$ Treated Peel Tissue During Scald Development}

To obtain information about the 1-MCP and $\mathrm{O}_{3}$ metabolic functions during scald development, primary metabolites were monitored at harvest, presymptomatic ( $0 \mathrm{~d}$ at room temperature) and symptomatic periods ( $5 \mathrm{~d}$ at room temperature) (Figure 2, Supplementary Table 1). Metabolic profiling in apple peel just after cold storage compared to harvest showed that the accumulation level of 23 metabolites varied, with 13 and 10 metabolites showing decreased and increased abundance, respectively (Figure 2). Several amino acids (e.g., valine, serine, threonine, and aspartic acid), sucrose (the main soluble sugar), malic acid (the main organic acid) as well as putrescine, hexadecane, 3-deoxy-glucosone, and 1-O-methylmannopyranoside decreased during cold storage (Figure 2; Supplementary Table 1). Meanwhile, metabolites whose abundance increased after cold period were mainly soluble sugars and soluble alcohols including arabinose, xylose, 1kestose, raffinose, fructose (soluble sugars), sorbitol, threitol, glycerol, arabitol (soluble alcohols), as well as dehydroascorbic acid (Figure 2). 
At the presymptomatic period 18,10 , and 16 metabolites showed altered abundance in response to $1-\mathrm{MCP}, \mathrm{O}_{3}$, and 1$\mathrm{MCP}+\mathrm{O}_{3}$ treatments, respectively (Figure 2). 1-MCP treatment led to an increase in the amount of citric acid, talose, serine, and threonine (Figure 2). Ozone-affected metabolites included glyceric acid and urea (both decreased levels), while the combined treatment $1-\mathrm{MCP}+\mathrm{O}_{3}$ affected the accumulation of sucrose (increased) and arabitol (decreased). Additionally, six metabolites were commonly repressed by all treatments, including glycerol, isoleucine, fumaric acid, threitol, and the lactones of gulonic acid and glucaric acid (Figure 2).

At postsymptomatic stage, 12 and 10 metabolites were influenced by individual 1-MCP and $\mathrm{O}_{3}$ applications, respectively while 19 metabolites showed altered accumulation following 1$\mathrm{MCP}+\mathrm{O}_{3}$ treatment (Figure 2). In response to 1-MCP there was an increased level of kestose (a trisaccharide deriving from sucrose), alanine and myoinositol (Figure 2). Meanwhile, $\mathrm{O}_{3}$ reduced the level of glycerol, isoleucine and turanose ( $\alpha$-d-glucopyranosyl$(1 \rightarrow 3)$ - $\alpha$-d-fructofuranose, an analog of sucrose), while 1-MCP $+\mathrm{O}_{3}$ increased that of glyceric acid, mannopyranoside, raffinose, maltose, sucrose but decreased that of quinic acid. Finally, five metabolites including valine, arabitol, glucaric acid, arabinose, and xylose were commonly affected by all treatments (Figure 2; Supplementary Table 1).

\section{Time-Resolved Proteomics in Apple Peel Exposed to 1-MCP and $\mathrm{O}_{3}$ Treatments}

To characterize the scald phenotypes (Figure 1), a comparative proteomic analysis of apple peel was performed. The volumes of 217 protein spots were modified by the treatments as inferred from Student's t-test and further validation using a 2.5 -fold threshold change. Following this approach, 87 proteins were uniquely identified (Supplementary Table 3A), which were sorted into 11 functional categories and 12 subcellular localizations according to Bevan et al. (1998) (Supplementary Figure 3; Supplementary Table 3; Supplementary Table 4). Multispot proteins, such as major allergen (15 spots), actin (11 spots), histone H4 (6 spots), and thiamine triazole synthase (4 spots) were also identified. Detailed information on the identified proteins is listed in Supplementary Tables 3, 4 and Supplementary Figure 5.

To examine protein changes in response to cold storage, samples collected at harvest were compared with controluntreated samples just after cold storage. As a result of cold, the levels of 62 proteins changed (Supplementary Figure 3; Supplementary Table 3B). These proteins are mainly located to cytosol (22.8\%), cytoplasm (13.9\%), chloroplast (13.9\%), and mitochondrion (11.4\%) (Supplemental Figure 3). Out of them, $26.6 \%$ pertain to metabolism, $22.8 \%$ to disease/defense, and $17.7 \%$ to energy (Supplementary Figure 3).

Proteins that were differentially accumulated in apple peel in response to treatments at the presymptomatic and symptomatic scald stages are listed in Figure 3. At presymptomatic period, proteins can be classified into three groups (Figure 3B): (i) a first group represented by 33 proteins whose abundance was altered only by 1-MCP; (ii) a second group containing 43 proteins whose accumulation was modified by the $\mathrm{O}_{3}$; and (iii) a third group consisting of 41 proteins whose accumulation level changed following the combined application of 1-MCP and $\mathrm{O}_{3}$ (Figure 3B). Among the groups of proteins showing significant modifications in their abundance at the presymptomatic period there were six that were commonly accumulated during all treatments. The identified proteins at presymptomatic period are mainly associated with metabolism (23.7\%) followed by disease/defense (18.4\%) and energy (13.2\%) (Figure 3D). They are mainly located at chloroplast (21.1\%), cytosol (15.8\%), and mitochondrion (10.5\%) (Supplementary Figure 3).

At the symptomatic stage, the $1-\mathrm{MCP}+\mathrm{O}_{3}$-responsive proteins could further be grouped as follows: a group of 71 proteins whose abundance was changed exclusively by 1-MCP; (ii) a second group of 12 proteins whose abundance was changed by $\mathrm{O}_{3}$; and a third group of 77 proteins accumulating under the $1-\mathrm{MCP}+\mathrm{O}_{3}$ combined treatment (Figure 3C). Identified proteins at the symptomatic stage are involved in metabolism (26\%), disease/defense (16\%), and energy (16\%) (Figure 3D). They are mainly localized to cytosol (22\%) and chloroplast (16\%) (Supplemental Figure 3). Five of them were commonly affected by all treatments (Figure 3E).

\section{Global Transcriptome Analysis Related to 1-MCP and $\mathrm{O}_{3}$ Function}

The transcriptomes of apple peel at the presymptomatic stage were analyzed to investigate early events preceding scald development. Data revealed that 6,892 transcripts were differentially expressed between treated and untreated apples (Figure 4A; Supplementary Table 5). A second analysis revealed that 1908 transcripts were regulated between $\mathrm{O}_{3}$ and $1-\mathrm{MCP}+\mathrm{O}_{3}$ (Figure 4A; Supplementary Table 5). Microarray data were also validated by RT-qPCR, on a subset of differentially expressed genes. Expression profiles assessed with microarrays or RTqPCR were similar $\left(\mathrm{R}^{2}=0.92\right.$ between LogRatio T/C and DDCt; Supplementary Figure 4; Supplementary Table 6).

Based on gene annotations, transcripts were classified into 33 functional categories (Figure 4B). Most of the identified transcripts were closely related to photosynthesis, especially following 1-MCP treatments, in which $99.2 \%$ of these genes were found to be upregulated. Furthermore, genes that are related to stress induction, protein accumulation, signaling, RNA, transport, and hormone metabolism were also affected (Figure 4B). Particularly, 1-MCP led to the alteration of the expression profile of 2,902 genes, of which 1,405 were upregulated, and 1,497 were downregulated. Furthermore, $\mathrm{O}_{3}$ regulated 1,625 transcripts, of which 1,069 induced and 556 reduced their expression level compared to control. The third comparison between $1-\mathrm{MCP}+\mathrm{O}_{3}$ and control involved 2,365 differentially expressed genes, of which 1,288 were upregulated and 1,077 were downregulated (Figure 4). Furthermore, 86 transcripts (38 upregulated and 48 downregulated) were affected by all treatments (Figure 4A). Finally, a comparison was performed between apples in $\mathrm{O}_{3}$-enriched atmosphere versus $1-\mathrm{MCP}+\mathrm{O}_{3}$ treatment. In this comparison, 1908 genes were differentially expressed, of which 853 were induced in 1- 

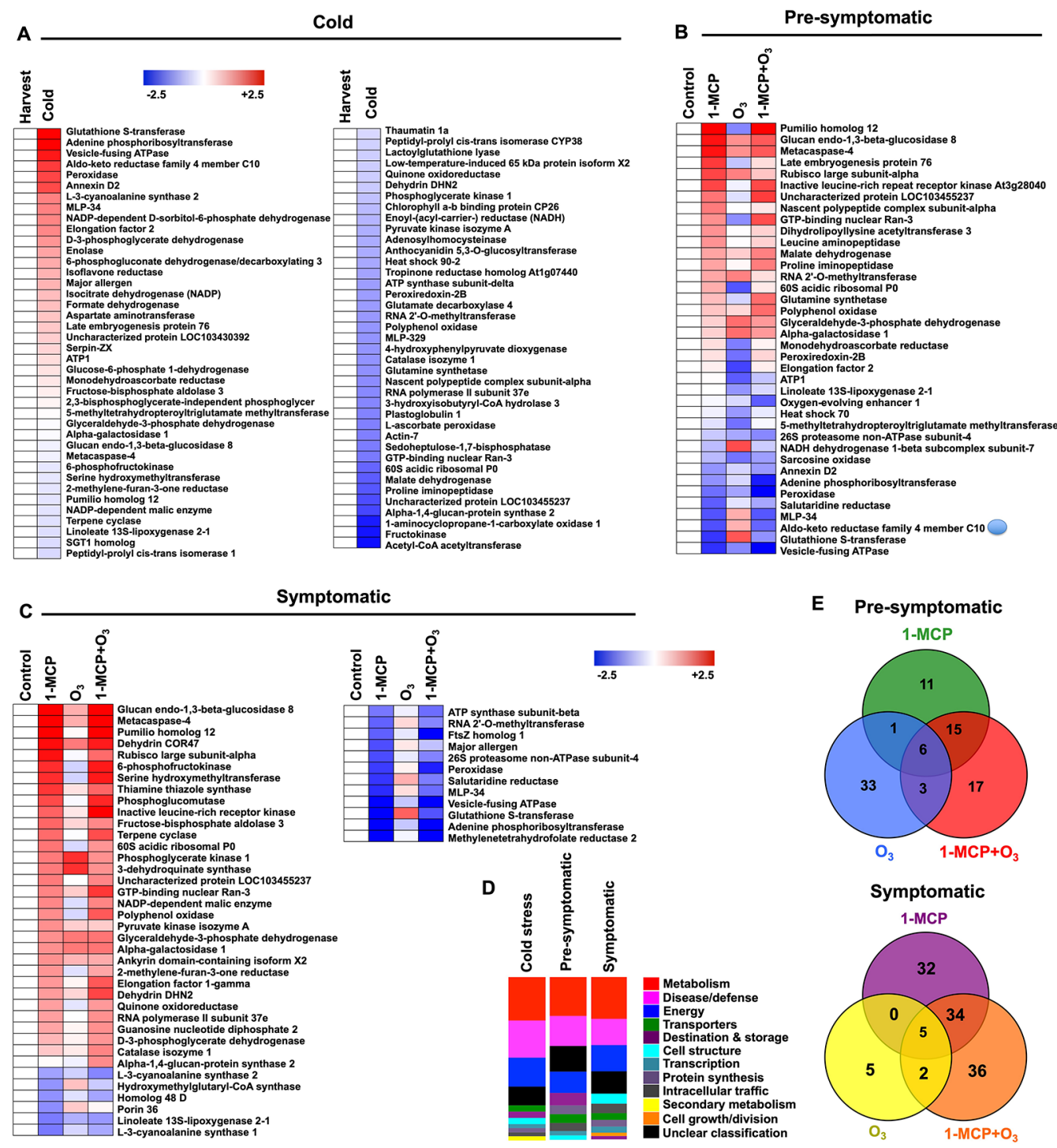

FIGURE 3 | Protein hallmarks in apple peel challenged with 1-MCP and $\mathrm{O}_{3}$. Changes in protein accumulation patterns in apple peel exposed to 1-MCP and $\mathrm{O}_{3}$ treatments in response to "cold" (A) as well as at "presymptomatic" (B) and "symptomatic" period (C). The heat map profiles depict the relative abundance of each protein either just after cold storage compared to harvest (for cold-affected proteins) or in 1-MCP and $\mathrm{O}_{3}$-treated samples compared to the abundance of untreated control (for proteins affected at "presymptomatic" and "presymptomatic" period). Fold change values are calculated as log2 ratio and were shown on a color scale, which is proportional to the abundance of each identified protein. Relative values for each protein abundance are provided in Supplementary Table 2. Functional categorization (D) of the identified proteins represented as a relative ratio proportional to the total number of the identified proteins that changed at each time (cold, presymptomatic, symptomatic stage). Venn diagrams illustrating the proteins that changed at presymptomatic and symptomatic period (E). Additional details for each protein are given in Supplementary Tables $\mathbf{3}$ and $\mathbf{4}$.

$\mathrm{MCP}+\mathrm{O}_{3}$ condition, while 1,055 were repressed, respectively (Figure 4).

\section{Analysis of Regulatory Networks and Modules in Apple Exposed to 1-MCP and $\mathrm{O}_{3}$}

To characterize the mechanisms underlying scald, the relationship between regulatory molecules, transcription factors (TFs) and downstream regulated genes was investigated, using expression data for genes and TFs incorporating protein and metabolite data. The output of a regulatory program is rarely due to the action of a single gene, being rather the result of the cooperation of multiple genes and their common regulation under the same TFs that result in the desired output. Notably, a group of coexpressed genes comprises a single module as well as the whole entire set of regulatory interactions between the TFs and the modules. Expression profiling was used to infer the regulatory networks that comprise regulated genes organized in modules as well as the TFs regulating these modules. The output of the LeMoNe algorithm is a set of modules of coexpressed 

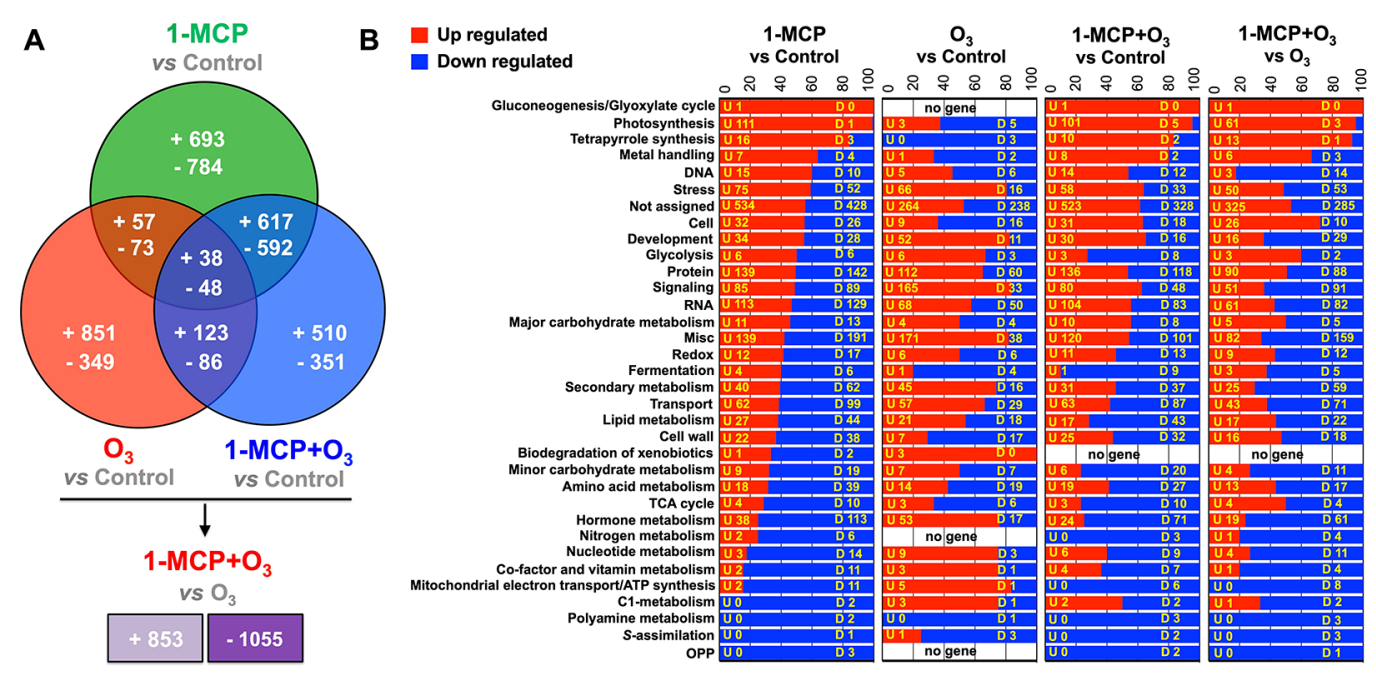

FIGURE 4 | Global gene expression analysis in apple peel exposed to 1-MCP and $\mathrm{O}_{3}$. Venn diagram representing the transcripts that upregulated and downregulated in apple peel tissues exposed to 1-MCP and $\mathrm{O}_{3}$ at "presymptomatic period" ( 0 d at room temperature following cold) (A) and functional categorization of the identified transcripts that modified among the microarray comparisons (B). " $\mathrm{U}$ " is related to the number of genes that upregulated between the 1-MCP and $\mathrm{O}_{3}$-treated fruits and control, while "D" is related to the number of genes that downregulated at each comparison. Additional details for each transcript are provided in Supplementary Table 5.

transcripts, providing a list of high-scoring TFs regulating the modules that were prioritized according to their corresponding scald syndrome. The algorithm assigns sets of TF regulators to each of the modules using a probabilistic scoring, taking into account the profile of the candidate regulator. Genes were first clustered into 235 modules (Supplementary Table 7) of which 22 were regulated by one or more TFs (Supplementary Table 7). This resulted in 46 transcription factor-module regulatory interactions that exceeded the above-random weight threshold (Supplementary Table 7). These TFs mainly include the following families: ARF (auxin response factors), bHLH (basic helix-loop-helix proteins playing a major role in jasmonates signaling), bZIP (basic leucine zipper proteins involved in photomorphogenesis, leaf and seed formation, energy homeostasis, and abiotic and biotic stress responses), CO-like (product of the CONSTANS gene acting between the circadian clock and genes controlling meristem identity), ERF (ethylene response factors coordinating stress signaling), FAR1, GRAS (named after the three members: GIBBERELLIC-ACID INSENSITIVE, REPRESSOR of GAI and SCARECROW, these TFs are involved in plant growth and development, HD-ZIP (homeodomain-leucine zipper involved in plant development and morphogenesis as well as responses to stresses), LBD (lateral organ boundary domain, acting as negative regulators of anthocyanin biosynthesis in Arabidopsis), MADS (MCM1, AGAMOUS, DEFICIENS, and SRF (serum response factor) TFs, involved in many aspects of plant development), MYB (myeloblastosis family of TFs acting as key factors in regulatory networks controlling plant development, metabolism and responses to stresses), NAC (named from the three genes: NAM, ATAF1 and -2 , and CUC2, these TFs are involved in the regulation of the transcriptional reprogramming associated with stress responses), NF-YA (NUCLEAR FACTOR$\mathrm{Y} A$, involved in plant growth and development), S1Fa (which specifically recognizes a negative element $(\mathrm{S} 1 \mathrm{~F})$ within the RPS1 promoter), TALE (transcription activator-like effector), TCP (plant-specific TEOSINTE BRANCHED 1, CYCLOIDEA, PCF1 TF family), Trihelix (TFs carrying three $\alpha$-helical sequences separated by loops or turns), WOX (plant-specific WUSCHEL-related homeobox TF gene family), YABBY (plantspecific TFs with zinc finger and high mobility group-related domains, involved in the specification of abaxial polarity in lateral organs) and ZF-HD (zinc finger homeobox family protein) (Supplementary Table 7).

\section{Key Changes in TFs-Gene-Protein- Metabolite Interactome Following 1-MCP and $\mathrm{O}_{3}$ Application}

Following the above network analysis, we examined the TFs-geneprotein-metabolite shift that was strongly affected by 1-MCP and $\mathrm{O}_{3}$ treatments (Figure 6). One of the main highlighted relationships shared between the two chemical treatments was the increase in PPO gene (MDP0000699845) was coregulated with HD-ZIP and encode PPO protein (Figure 6; Supplementary Table 7). Additionally, TFs and related transcripts for five putative proteins, namely glucan glucosidase 8, 6-phosphofructokinase, FtsZ homolog 1, ATP synthase subunit-beta and lipid-transfer protein were positively or negatively affected by treatments (Figure 6). A notable feature of our analysis was that a large number of TFs (HD-ZIP, FAR1, ZF-HD, NF-YA, MYB, S1Fa-like, YABBY, and $B H L H)$ along with downstream target glutathione $S$-transferase (GSTs) genes (MDP0000178304, MDP0000256360, $M D P 0000252292, M D P 0000805474, M D P 0000766223$, $M D P 0000261432, M D P 0000722969$, and MDP0000566567) and 
corresponding GSTs proteins showed the most striking treatmentspecific regulation (Figure 6; Supplementary Table 7), indicating that GSTs play a key role in scald.

\section{DISCUSSION}

Despite the economical importance of superficial scald in apple, the etiology and biochemistry that lead to the development of this disorder are not completely understood (Lurie and Watkins, 2012; Storch et al., 2017). In this study, we found that fruits exposed to 1-MCP exhibited inhibition of ethylene-dependent ripening processes (Figures 1C-G; Supplementary Figure 1) and displayed considerably reduced scald symptoms (Figures 1A, B). We previously found that kiwifruit ripening and ethylene production were depressed by $\mathrm{O}_{3}$ (Minas et al., 2014; Minas et al., 2018). In marked contrast with the situation observed with kiwifruit, the ripening behavior (Figures $\mathbf{1 C}-\mathbf{G}$ ) as well as the activities of ACS and ACO, and the ACC and MACC levels along with ethylene production (Figures 1C-G) remained unaffected in $\mathrm{O}_{3}$-treated apples (Supplementary Figure 1). This indicates that the ripening effects of $\mathrm{O}_{3}$ are different depending on the fruit species and/or tissue analyzed. However, the data from the current study point to a novel observation, namely that $\mathrm{O}_{3}$ noticeably induced visible scald injury in apple (Figures 1A, B). Another important result revealed by this study was that fruits subjected to 1-MCP in the presence of $\mathrm{O}_{3}$ exhibited scaldhealthy phenotypes (Figures 1A, B), confirming that 1-MCP is a very efficient tool to prevent apple scald (Lurie and Watkins, 2012). Such distinct 1-MCP- and $\mathrm{O}_{3}$-driven scald features (Figures 1A, B) provide a relevant model for exploring the mechanisms associated with apple cold responses as well as with scald prevention/sensibility.

Long term cold exposure induced major metabolic and biochemical changes in fruits (Molassiotis et al., 2013). Accordingly, we observed a strong reduction in several amino acids, such as aspartic acid, glutamic acid, serine, threonine, and valine in apple peel following cold storage (Figure 2). Proteins coding numerous antioxidant-related enzymes (e.g., peroxidase and monodehydroascorbate reductase, and NADPH-generating systems (e.g., 6-phosphogluconate dehydrogenase) along with energy-associated enzymes (e.g., adenine phosphoribosyltransferase, ATP1 and vesicle-fusing ATPase) were induced by cold (Figure 3A; Supplementary Table 3B). Also, various ripening enzymes (e.g., ACO, malate dehydrogenase, and fructokinase) were repressed by cold (Figure 3A; Supplementary Table 3B).

Metabolome data indicated that unlike $\mathrm{O}_{3}$ application, the 1MCP treatment provoked the accumulation of several amino acids both before and during scald. Our results, when taken together with previous ones (Osuna et al., 2007; Less and Galili, 2008), suggest important roles for amino acid biosynthesis in scald responses. In this regard, an intriguing observation was the greater accumulation of threonine and valine in 1-MCP-treated compared to $\mathrm{O}_{3}$-treated fruits (Figure 2), particularly indicating that different scald phenotypes may reflect specific reprogramming in branchedchain amino acids (BCAAs). It has been shown that BCAAs accumulation may serve as a substrate for the synthesis of stress- induced proteins and that BCAAs may act as signaling molecules to regulate gene expression in response to cold (Goddard et al., 1993). In agreement with recent data obtained in peach fruit showing that BCAAs accumulation together with the upregulation of genes encoding BCAAs-rich proteins confer tolerance against cold injury (Tanou et al., 2017). Furthermore, steady-state levels of serine exhibited distinct patterns in 1-MCP and $\mathrm{O}_{3}$ treated samples (Figure 2). We have shown that protein abundance of D-3-phosphoglycerate dehydrogenase (PHGDH) and serine hydroxymethyltransferase (SHMT) was induced by both 1-MCP treatments but depressed by $\mathrm{O}_{3}$ alone application (Figure 3C; Supplementary Table 3). PHGDH catalyzes the transition of 3phosphoglycerate into 3-phosphohydroxypyruvate, which is the committed step in the phosphorylated pathway of L-serine biosynthesis while SHMT catalyzes the reversible interconversion of serine and glycine with tetrahydrofolate serving as the onecarbon carrier. Given the role of serine in photorespiration in mitigating production of ROS at the chloroplast (Leegood et al., 1995), the observed stimulation of serine metabolism along with the upregulation of various photosynthetic genes by 1-MCP (Figure 4B) might result in an activation of the antioxidant defenses leading to a reduced level of chloroplast oxidation and reduced scald susceptibility. Consistent with this possibility, photorespiratory Arabidopsis mutants specifically defective in SHMT showed spontaneous formation of chlorotic and necrotic lesions (Moreno et al., 2005).

A set of apple peel proteins displayed high accumulation levels in healthy fruits (1-MCP treated), both at presymptomatic and especially at symptomatic periods, whereas $\mathrm{O}_{3}$-treated fruits had decreased scald symptoms (Figures 3A, B). This implies, quite remarkably, that a specific $1-\mathrm{MCP}$ and $\mathrm{O}_{3}$-specific proteome remodeling occurs that could be correlated with scald phenotypes. Posttranscriptional/translational control of gene expression is a powerful strategy for fruit cells to adapt to postcold ripening period as this process is controlled by various RNA-binding proteins (Huh and Paek, 2014). At prosymptomatic and symptomatic periods, we observed in 1-MCP exposed fruits an increased abundance of Pumilio 12 (PUM12) (Supplementary Tables 3C, D), a protein that binds to sequences in the $3^{\prime}$ UTRs of target mRNAs through their PUMILIO homology domains, suggesting a correlation between PUM12 accumulation and scald prevention. This protein would participate in scald response through binding to specific regulatory cis-elements of their mRNA targets, to regulate RNA translation (Lee et al., 2016) and thus involved in protein synthesis. There are examples in plants indicating that nucleo-cytoplasmic trafficking of proteins can also affect posttranscriptional regulation, such as mRNA processing and RNA trafficking (Wang et al., 2010). Interestingly, we found that the abundance of the GTP-binding nuclear protein Ran-3, which is required for nucleo-cytoplasmic protein/RNA partitioning, along with the abundance of elongation factor 2 (eEF2; a GTPbinding protein), was both higher in 1-MCP-treated than in $\mathrm{O}_{3^{-}}$ scalded fruits (Supplementary Table 3). It is thus likely that scald prevention is associated with nucleo-cytoplasmic transport of proteins and RNA, possibly because this mechanism allows for 
quick responses from cold to higher temperature transition without de novo protein and RNA syntheses. Such a mechanism seems to be impaired in fruits exposed to the single $\mathrm{O}_{3}$ treatment, since we found, for example, that the accumulation of the Ran-3 protein was suppressed by $\mathrm{O}_{3}$ (Supplementary Table 3).

Among the multiple molecular mechanisms underlying cold responses, alterations of the protein translation machinery affecting the rate and selectivity of stress-related protein biosynthesis may play a central role (Wang et al., 2017). The higher accumulation of the $60 \mathrm{~S}$ acidic ribosomal protein P1, involved in the elongation step of protein synthesis, observed at both pro-symptomatic and symptomatic time following 1-MCP application (Supplementary Tables 3C, D) should contribute to scald prevention. Noticeably in the context of this work, Nakaminami et al. (2014) showed that the 60S acidic ribosomal protein $\mathrm{P} 1$ is involved in cold acclimation in Arabidopsis. Exposure to $\mathrm{O}_{3}$ alone suppressed the accumulation of several stress-related proteins, such as the late embryogenesis protein 76, peroxiredoxin-2B and monodehydroascorbate reductase (Supplementary Table 3), which may well explain the aberrant scald defect in $\mathrm{O}_{3}$-treated apple (Figures 1A, B).

A large number of apple genes exhibited 1-MCP and $\mathrm{O}_{3}$ associated patterns of expression (Figure 4) that could possibly affect scald responses (Figures 1A, B). We focused on the genes that displayed opposite distinct patterns of regulation between 1$\mathrm{MCP}$ and $\mathrm{O}_{3}$. In this set of genes we found a strong induction of various photosynthetic genes only following 1-MCP treatments (Figure 4). This fact fits well with the 1-MCP accociated retention of green color in the peel of 'Granny Smith' apples (Figure 1A), suggesting that the photosynthetic machinery could be accociated with scald. This 1-MCP-exclusive photosyntetic group includes genes annotated as photosystem I subunit D-2 (PSAD-2; MDP0000700880), photosystem I reaction center subunit PSI-N (PSAN; MDP0000655277), photosystem II subunit P-1 (PSBP-1; MDP0000361338), PsbQ-like 2 (MDP0000481445), photosystem II subunit Q-2 (PSBQ/PSBQ2; $M D P 0000715912)$ rubisco activase (RCA; MDP0000223905), ribulose bisphosphate carboxylase (RBC; MDP0000185022), and ribulose bisphosphate carboxylase (small chain) protein (MDP0000185022) (Supplementary Table 5). The upregulation of photosynthetic genes (Figure 4) could be linked to the inhibition of ethylene synthesis and signaling by 1-MCP, which in turn might increase the efficiency of ROSscavenging system (Foyer and Shigeoka, 2010), leading to lower oxidative stress and scald prevention. We noted that the expression of several stress-related transcripts, including those encoding leucine-rich repeat protein (MDP0000331536), HVA22 homologue D (MDP0000574524; homologous to a eukaryote specific ABA- and stress-inducible gene first isolated from barley) and HSP20-like chaperones (MDP0000574524) were solely induced by 1-MCP (Supplementary Table 5). Given that these genes are involved in cold acclimation (Shen et al., 2001; Lopes-Caitar et al., 2013; Liao et al., 2017), our data suggests that the induction of stress-related gene expression by 1-MCP could contribute to apple fruit tolerance against cold stress. In addition, 1-MCP repressed several ethylene signaling genes, such as ethylene response sensor 1 (ERS1; MDP0000242413) (Supplementary Table 5). We also observed a strong downregulation of various genes only by 1-MCP that could be directly linked to scald. An interesting example is the downregulation of the gene encoding farnesyl diphosphate synthase 2 (FPS2; MDP0000198736) by 1-MCP, whose expression was found to be tightly linked to scald syndrome (Tsantili et al., 2007; Karagiannis et al., 2018b), supporting the present scald characterization.

The expression of several transcripts was exclusively affected by $\mathrm{O}_{3}$ and therefore might affect scald development (Figure 4). In particular, $\mathrm{O}_{3}$ appeared to upregulate receptor-like proteins 15 (RLP, an important class of cell-surface receptors; $M D P 0000302222)$ and naringenin-chalcone synthase (CHS, the first committed enzyme in flavonoid biosynthesis; MDP0000432621) (Supplementary Table 5). Studies on several RLPs genes have revealed gene expression changes, as well as the emergence of phenotypic alterations, following application of specific elicitors (Wang et al., 2010). This result highlights that $\mathrm{O}_{3}$-enriched cold storage atmosphere stimulated RLP15 expression, presumably because of $\mathrm{O}_{3}$ action as a signal molecule for the activation of cell-surface receptors to perceive $\mathrm{O}_{3}$-specific signals. In the flavonoid pathway CHS catalyzes the stepwise condensation of three acetate residues from malonylCoA with the phenylpropanoid biosynthetic intermediate $p$ coumaroyl CoA to form naringenin chalcone. Naringeninchalcone synthase was previously shown to be $\mathrm{O}_{3}$-sensitive on the basis of the appearance of macroscopic injury in plant cells (Paolacci et al., 2002). This supports the possibility that susceptibility to scald might rest on a sequence of molecular events similar to that leading to programmed cell death (PCD), which was indirectly observed as one of the scald symptoms (Busatto et al., 2014; Karagiannis et al., 2018b).

To characterize the mechanism of scald development, the transcript, protein and metabolite data sets were integrated using bioinformatics tools to identify TFs regulating gene modules with similar coexpression patterns (Figure 5). Based on network analysis, we constructed an integrated analysis of TFs-geneprotein-metabolite data sets and we focused on certain important interactome shift that dispayed redundant changes in response to appied treatments (Figure 6). Using this approach, we observed that PPO was strongly affected by treatments, which is consistent with its effect on scald-derived browning hallmarks in apple skin (Boss et al., 1995; Mayer, 2006; Busatto et al., 2014). Our analysis identified that genes coregulated by TFs encoding nine GTS proteins disclosed completely distinct regulation in response to $1-\mathrm{MCP}$ and $\mathrm{O}_{3}$ (Figure 6). Recent research also uncovered an important role of GSTs in scald development (Du et al., 2017; Karagiannis et al., 2018b; Wang et al., 2018) thereby pointing out these enzymes as promising candidates for further functional characterizations. What then might be the role of GSTs in scald physiology? It is 

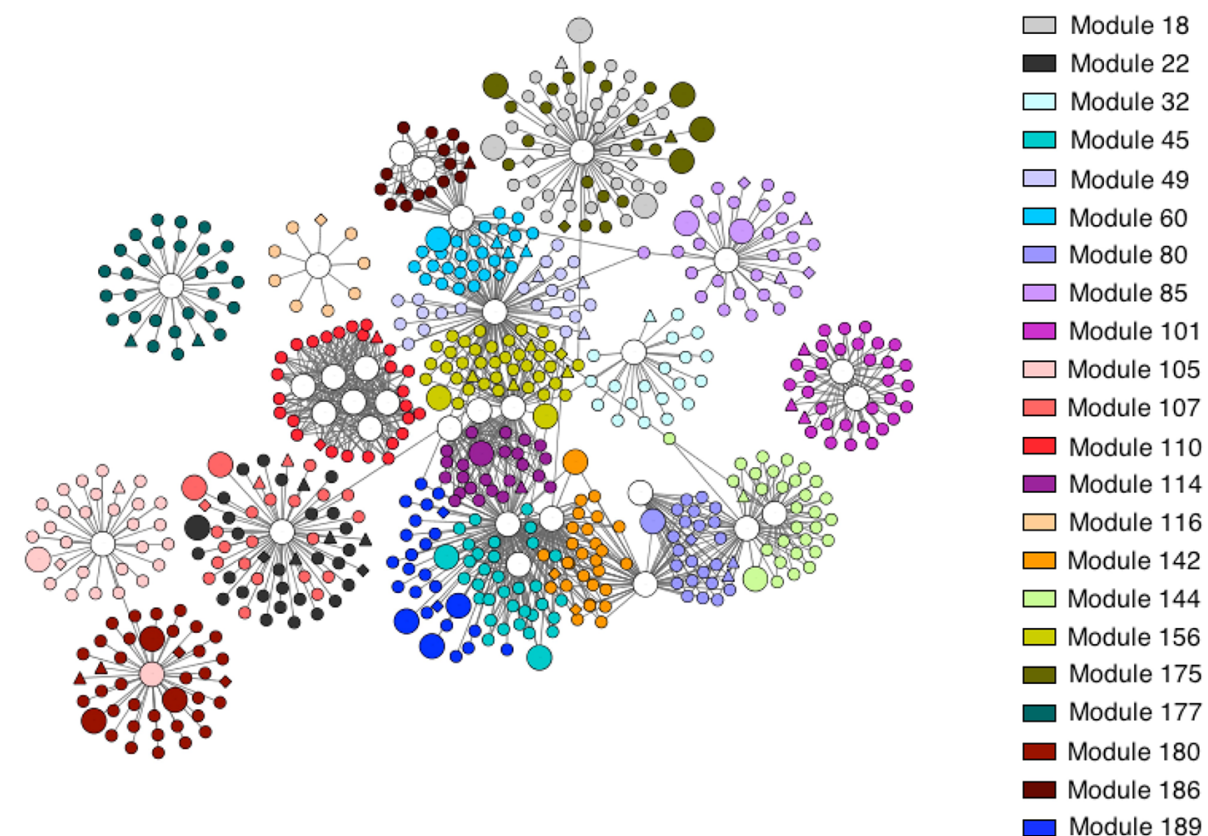

FIGURE 5 | Transcriptional regulatory network in apple peel at pro-symptomatic period. Nodes represent genes, edges regulatory interactions between a transcription factor and a gene. Triangle-shaped nodes represent nodes with significant protein expression; diamond-shaped nodes represent genes with significant metabolite expression; larger circles represent transcription factors. Modules are color-coded as indicated in the inset.

possible that some apple GSTs may participate in the detoxification of reactive aldehydes and related compounds that are generated by the loss of membrane integrity during scald development (Busatto et al., 2018). We found that several other aldehyde scavengers, such as aldo-keto reductase family 4 member $\mathrm{C} 10$ and glyceraldehyde-3-phosphate dehydrogenase, were stimulated by $\mathrm{O}_{3}$ at pro-symptomatic period (Figure 3). The idea that proper lipid modification is needed to activate the detoxification of lipid peroxidation-produced toxic compounds is also supported by the observed similar expression pattern of GSTs with the lipid-transfer proteins (LTPs) (Figure 6), which are required for assembly of the water-proof lipid barriers-such as cutin and cuticular wax and suberin-largely present on apple peel surface (Beisson et al., 2012). Particularly, we observed that LTP (MDP0000722969 and MDP0000188674) and GSTs (encoded by MDP0000566567 and MDP0000549134) were commonly regulated by basic helix-loop-helix (bHLH) TF, suggesting that this TF could be critical for scald development. Feng et al. (2012) also showed that the apple bHLH gene MdCIbHLH1 (Cold-Induced bHLH1) was induced in response to cold stress. It has been demonstrated that the MdCIbHLH1 protein bound to the promoters of $M d C B F 2$ and favorably contributed to cold tolerance in transgenic apple plants by upregulating the expression of $M d C B F 2$ through the ICE-CBF/ DREB1 pathway (Feng et al., 2012). It is widely recognized that the ICE (Inducer of CBF Expression)-C-repeat binding factor (CBF) transcriptional regulatory cascade globally regulates coldresponse in Arabidopsis (Knight and Knight, 2012). There is strong evidence that ICE1, a bHLH transcription factor, directly binds to cis-elements (CANNTG) in the CBF3/DREB1a promoter (Chinnusamy et al., 2003), thereby linking bHLH with the ICE-CBF/ DREB1 cold pathway. In parallel, ethylene signaling was shown to negatively regulate plant cold stress responses by repressing the ICECBF/DREB1 system in Arabidopsis (Shi et al., 2012). This link between ethylene and postcold apple metabolism is further supported by the identified function of two ERF TFs (encoded by MDP0000932292 and MDP0000127134) toward 1-MCP and $\mathrm{O}_{3}$ treatments (Supplementary Table 7). An alternative possibility to account for the observed transcriptionally upregulation of GST in all scald-affected circumstances (control and $\mathrm{O}_{3}$ ) could be that GST is induced as a consequence of cold stress and scald expression. It has been reported that the levels of glutathione (GSH), together with the GSH metabolite cysteinil-glycine, were increased in stressed 'Granny Smith' fruits undergoing scald while decreased in 1-MCP treated fruits (Zermiani et al., 2015), suggesting that GSH cycling was regulated by scald probably to support ROS control. This hypothesis was reinforced by the profile of a plethora of ROS metabolising genes and enzymes in the scald-affected apple peel (Supplementary Tables 4 and 5). Further research is needed to reveal the exact functions of GST in scald.

\section{CONCLUSION}

This work provides novel information as to how 1-MCP and especially $\mathrm{O}_{3}$ may regulate scald expression, while also offering a 


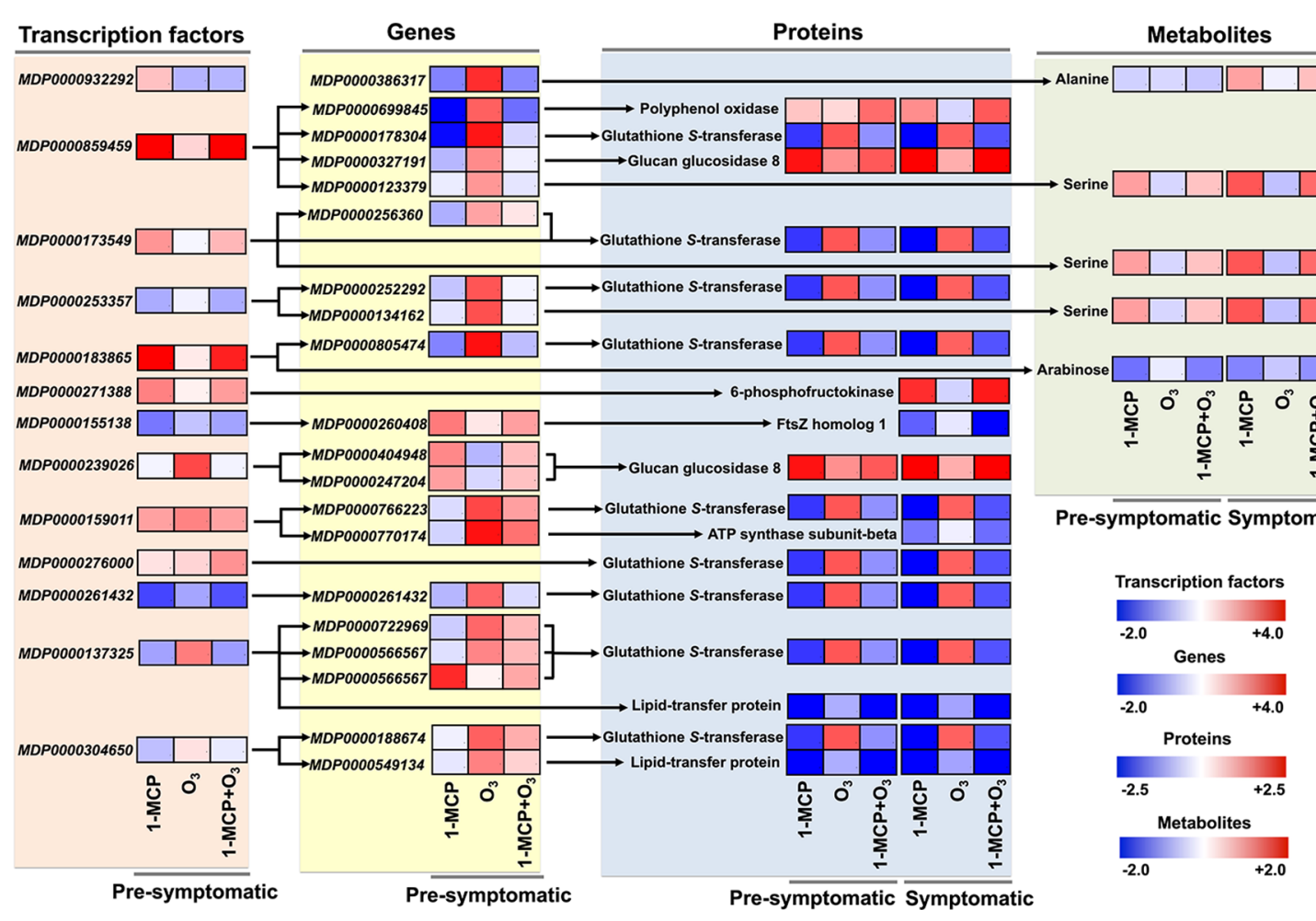

FIGURE 6 | Key TFs-gene-protein-metabolite interactome shift that affected by 1-MCP and $\mathrm{O}_{3}$. Schematic representation showing a TFs-gene-protein-metabolite interactome shift, based on network analysis, that was remarkably altered in response to chemical treatments. The heat maps represent the relative level of each component at presymptomatic and symptomatic stage. The color scales that are proportional to the ratio of each identified component shows the fold change between treated and control fruits. Relative expression data are shown in Supplementary Tables 1, 2, and 5. MDP0000386317: ALD1 (AGD2 - LIKE DEFENSE RESPONSE PROTEIN1); transaminase, MDP0000699845: polyphenol oxidase, MDP0000178304: ATGSTU8 (Arabidopsis thaliana glutathione S-transferase (class tau) 8); glutathione transferase, MDP0000327191: BG3 (BETA-1,3-GLUCANASE 3); hydrolase, hydrolyzing O-glycosyl compounds, MDP0000123379: protein kinase family, MDP0000256360: ATGSTF8 (glutathione S-transferase 8); glutathione S-transferase, MDP0000252292: ATGSTF12 (glutathione S-transferase 26); glutathione transferase, MDP0000134162: RLK1 (RECEPTOR-LIKE PROTEIN KINASE 1); carbohydrate binding/kinase, MDP0000805474: ATGSTU8 (Arabidopsis thaliana glutathione S-transferase (class tau) 8); glutathione transferase, MDP0000260408: transducin family protein/WD-40, MDP0000404948: glycosyl hydrolase family 17 protein, MDP0000247204: glycosyl hydrolase family 17 protein, MDP0000766223: ATGSTU8 (Arabidopsis thaliana g/utathione S-transferase (class tau) 8); glutathione transferase, MDP0000770174: PAD4 (PHYTOALEXIN DEFICIENT 4); triacylglycerol lipase, MDP0000261432: plant-specific YABBY family protein, MDP0000722969: ATGSTU25 (Arabidopsis thaliana glutathione S-transferase (class tau) 25); glutathione transferase, MDP0000566567: ATGSTU21 (Arabidopsis thaliana glutathione S-transferase (class tau) 21); glutathione transferase, MDP0000188674: In2-1 protein, putative, MDP0000549134: protease inhibitor/seed storage/lipid transfer protein (LTP).

framework for the gene, proteins, metabolite, and transcriptional networks that are functioning during the early and late stages of scald development. Data of the experimental 1-MCP and $\mathrm{O}_{3}$ system described in this article supported the importance of accumulation of several amino acids, including branched-chain amino acids, as well as the nucleo-cytoplasmic transport of proteins and RNA protein translation in scald. Interestingly, the 1-MCP induced scald tolerance was correlated with the active expression of several genes in apple peel that are involved in photosynthesis, stress responses, flavonoid biosynthesis and ethylene signaling. We also constructed a trans-omic network of TFs using a combination of data generated in this study. This approach suggested a crucial role of PPO and especially GST protein in scald progress. Altogether, this integrated study could help to better understand regulatory mechanisms underlying scald in apple fruit.

\section{DATA AVAILABILITY STATEMENT}

Microarray data have been submitted to the Gene Expression Omnibus under the accession number GSE133456. The proteomic datasets generated for this study can be found in the ProteomeXchange accession PXD016849.

\section{AUTHOR CONTRIBUTIONS}

EK and AM conceived the project and its components. EK, GT, and MMi collected samples and performed physiological analysis. EK, MO, and FL conducted gene expression and data analysis. EK, GT, MS, and DJ acquired and analyzed proteomic data. FS and AF acquired and analyzed metabolic data. MMa performed bioinformatics analysis. EK and AM wrote the 
manuscript. All authors read, revised, and approved the final manuscript.

\section{FUNDING}

The research work was partially supported by the Hellenic Foundation for Research and Innovation (H.F.R.I.) under the "First Call for H.F.R.I. Research Projects to support Faculty

\section{REFERENCES}

Ainalidou, A., Tanou, G., Belghazi, M., Samiotaki, M., Diamantidis, G., Molassiotis, A., et al. (2016). Integrated analysis of metabolites and proteins reveal aspects of the tissue-specific function of synthetic cytokinin in kiwifruit development and ripening. J. Proteomics 143, 318-333. doi: 10.1016/j.jprot.2016.02.013

Beisson, F., Li-Beisson, Y., and Pollard, M. (2012). Solving the puzzles of cutin and suberin polymer biosynthesis. Curr. Opin. Plant Biol. 15, 329-337. doi: 10.1016/j.pbi.2012.03.003

Bevan, M., Bancroft, I., Bent, E., Love, K., Goodman, H., Dean, C., et al. (1998). Analysis of $1.9 \mathrm{Mb}$ of contiguous sequence from chromosome 4 of Arabidopsis thaliana. Nature 391, 485-488. doi: 10.1038/35140

Boss, P. K., Gardner, R. C., Janssen, B. J., and Ross, G. S. (1995). An apple polyphenol oxidase cDNA is up-regulated in wounded tissues. Plant Mol. Biol. 27, 429-433. doi: 10.1007/BF00020197

Bulens, I., Van de Poel, B., Hertog, M. L. A. T. M., De Proft, M. P., Geeraerd, A. H., and Nicolaï, B. M. (2011). Protocol: an updated integrated methodology for analysis of metabolites and enzyme activities of ethylene biosynthesis. Plant Methods 7, 17. doi: 10.1186/1746-4811-7-17

Busatto, N., Farneti, B., Tadiello, A., Vrhovsek, U., Cappellin, L., Biasioli, F., et al. (2014). Target metabolite and gene transcription profiling during the development of superficial scald in apple (Malus $\mathrm{x}$ domestica Borkh). BMC Plant Biol. 14, 193. doi: 10.1186/s12870-014-0193-7

Busatto, N., Farneti, B., Commisso, M., Bianconi, M., Iadarola, B., Zago, E., et al. (2018). Apple fruit superficial scald resistance mediated by ethylene inhibition is associated with diverse metabolic processes. Plant J. 93, 270-285. doi: 10.1111/tpj.13774

Celton, J. M., Gaillard, S., Bruneau, M., Pelletier, S., Aubourg, S., MartinMagniette, M. L., et al. (2014). Widespread anti-sense transcription in apple is correlated with siRNA production and indicates a large potential for transcriptional and/or post-transcriptional control. New Phytol. 203, 287299. doi: 10.1111/nph.12787

Chinnusamy, V., Ohta, M., Kanrar, S., Lee, B. H., Hong, X., and Agarwal, M.,. Z. J. (2003). ICE1: a regulator of cold-induced transcriptome and freezing tolerance in Arabidopsis. Genes Dev. 17, 1043-1054. doi: 10.1101/gad.1077503.CRT

Daccord, N., Celton, J. M., Linsmith, G., Becker, C., Choisne, N., Schijlen, E., et al. (2017). High-quality de novo assembly of the apple genome and methylome dynamics of early fruit development. Nat. Genet. 49, 1099-1106. doi: 10.1038/ ng.3886

Dheilly, E., Gall, S., Le Guillou, M. C., Renou, J. P., Bonnin, E., et al. (2016). Cell wall dynamics during apple development and storage involves hemicellulose modifications and related expressed genes. BMC Plant Biol. 16, 201. doi: 10.1186/s12870-016-0887-0

Du, L., Song, J., Campbell Palmer, L., Fillmore, S., and Zhang, Z. Q. (2017). Quantitative proteomic changes in development of superficial scald disorder and its response to diphenylamine and 1-MCP treatments in apple fruit. Postharv. Biol. Technol. 123, 33-50. doi: 10.1016/j.postharvbio.2016.08.005

Espley, R. V., Hellens, R. P., Putterill, J., Stevenson, D. E., Kutty-Amma, S., and Allan, A. C. (2007). Red colouration in apple fruit is due to the activity of the MYB transcription factor, MdMYB10. Plant J. 49, 414-427. doi: 10.1111/ j.1365-313X.2006.02964.x

Feng, X. M., Zhao, Q., Zhao, L. L., Qiao, Y., Xie, X., Bin,, et al. (2012). The cold-induced basic helix-loop-helix transcription factor gene MdCIbHLH1 encodes an ICE-like protein in apple. BMC Plant Biol. 12, 22. doi: 10.1186/1471-2229-12-22

Fernie, A. R., Aharoni, A., Willmitzer, L., Stitt, M., Tohge, T., Kopka, J., et al. (2011). Recommendations for reporting metabolite data. Plant Cell 23, 24772482. doi: $10.1105 /$ tpc. 111.086272 members and Researchers and the procurement of high-cost research equipment grant" (Project Number: 633; GERASKO).

\section{SUPPLEMENTARY MATERIAL}

The Supplementary Material for this article can be found online at: https://www.frontiersin.org/articles/10.3389/fpls.2020.00008/ full\#supplementary-material

Foyer, C. H., and Shigeoka, S. (2010). Understanding oxidative stress and antioxidant functions to enhance photosynthesis. Plant Physiol. 155, 93-100. doi: 10.1104/pp.110.166181

Gapper, N. E., Hertog, M. L. A. T. M., Lee, J., Buchanan, D. A., Leisso, R. S., Fei, Z., et al. (2017). Delayed response to cold stress is characterized by successive metabolic shifts culminating in apple fruit peel necrosis. BMC Plant Biol. 17, 77. doi: 10.1186/s12870-017-1030-6

Goddard, N. J., Dunn, M. A., Zhang, L., White, A. J., Jack, P. L., and Hughes, M. A. (1993). Molecular analysis and spatial expression pattern of a lowtemperature-specific barley gene, blt101. Plant Mol. Biol. 23, 871-879. doi: 10.1007/BF00021541

Huh, S. U., and Paek, K. H. (2014). APUM5, encoding a Pumilio RNA binding protein, negatively regulates abiotic stress responsive gene expression. BMC Plant Biol. 14, 75. doi: 10.1186/1471-2229-14-75

Hummel, J., Strehmel, N., Selbig, J., Walther, D., and Kopka, J. (2010). Decision tree supported substructure prediction of metabolites from GC-MS profiles. Metabolomics 6, 322-333. doi: 10.1007/s11306-010-0198-7

Karagiannis, E., Tanou, G., Samiotaki, M., Michailidis, M., Diamantidis, G., Minas, I. S., et al. (2016). Comparative physiological and proteomic analysis reveal distinct regulation of peach skin quality traits by altitude. Front. Plant Sci. 7, 114. doi: $10.3389 /$ fpls.2016.01689

Karagiannis, E., Michailidis, M., Karamanoli, K., Lazaridou, A., Minas, I. S., and Molassiotis, A. (2018a). Postharvest responses of sweet cherry fruit and stem tissues revealed by metabolomic profiling. Plant Physiol. Biochem. 127, 478484. doi: 10.1016/j.plaphy.2018.04.029

Karagiannis, E., Michailidis, M., Tanou, G., Samiotaki, M., Karamanoli, K., Avramidou, E., et al. (2018b). Ethylene -dependent and -independent superficial scald resistance mechanisms in 'Granny Smith' apple fruit. Sci. Rep. 8, 1-16. doi: 10.1038/s41598-018-29706-x

Knight, M. R., and Knight, H. (2012). Low-temperature perception leading to gene expression and cold tolerance in higher plants. New Phytol. 195, 737-751. doi: 10.1111/j.1469-8137.2012.04239.x

Lee, S., Kopp, F., Chang, T. C., Sataluri, A., Chen, B., Sivakumar, S., et al. (2016). Noncoding RNA NORAD regulates genomic stability by sequestering PUMILIO proteins. Cell 164, 69-80. doi: 10.1016/j.cell.2015.12.017

Leegood, R. C., Lea, P. J., Adcock, M. D., and Hausler, R. E. (1995). The regulation and control of photorespiration. J. Exp. Bot. 46, 1397-1414. doi: 10.1093/jxb/ 46.special_issue.1397

Less, H., and Galili, G. (2008). Principal transcriptional programs regulating plant amino acid metabolism in response to abiotic stresses. Plant Physiol. 147, 316 330. doi: $10.1104 /$ pp.108.115733

Liao, Y., Hu, C., Zhang, X., Cao, X., Xu, Z., Gao, X., et al. (2017). Isolation of a novel leucine-rich repeat receptor-like kinase (OsLRR2) gene from rice and analysis of its relation to abiotic stress responses. Biotechnol. Biotechnol. Equip. 31, 51-57. doi: 10.1080/13102818.2016.1242377

Livak, K. J., and Schmittgen, T. D. (2001). Analysis of relative gene expression data using real-time quantitative PCR and the 2- $\Delta \Delta \mathrm{CT}$ method. Methods 25, $402-$ 408. doi: $10.1006 /$ meth.2001.1262

Lombardo, V. A., Osorio, S., Borsani, J., Lauxmann, M. A., Bustamante, C. A., Budde, C. O., et al. (2011). Metabolic profiling during peach fruit development and ripening reveals the metabolic networks that underpin each developmental stage. Plant Physiol. 157, 1696-1710. doi: 10.1104/ pp.111.186064

Lopes-Caitar, V. S., de Carvalho, M. C. C. G., Darben, L. M., Kuwahara, M. K., Nepomuceno, A. L., Dias, W. P., et al. (2013). Genome-wide analysis of the Hsp20 gene family in soybean: Comprehensive sequence, genomic 
organization and expression profile analysis under abiotic and biotic stresses. BMC Genomics 14, 577. doi: 10.1186/1471-2164-14-577

Luedemann, A., Strassburg, K., Erban, A., and Kopka, J. (2008). TagFinder for the quantitative analysis of gas chromatography - mass spectrometry (GC-MS)based metabolite profiling experiments. Bioinformatics 24, 732-737. doi: 10.1093/bioinformatics/btn023

Lurie, S., and Watkins, C. B. (2012). Superficial scald, its etiology and control. Postharv. Biol. Technol. 65, 44-60. doi: 10.1016/j.postharvbio.2011.11.001

Mary-Huard, T., Aubert, J., Mansouri-Attia, N., Sandra, O., and Daudin, J. J. (2008). Statistical methodology for the analysis of dye-switch microarray experiments. BMC Bioinf. 9, 1-11. doi: 10.1186/1471-2105-9-98

Mayer, A. M. (2006). Polyphenol oxidases in plants and fungi: going places? A Rev. Phytochem. 67, 2318-2331. doi: 10.1016/j.phytochem.2006.08.006

Minas, I. S., Vicente, A. R., Dhanapal, A. P., Manganaris, G. A., Goulas, V., Vasilakakis, M., et al. (2014). Ozone-induced kiwifruit ripening delay is mediated by ethylene biosynthesis inhibition and cell wall dismantling regulation. Plant Sci. 229, 76-85. doi: 10.1016/j.plantsci.2014.08.016

Minas, I. S., Tanou, G., Karagiannis, E., Belghazi, M., and Molassiotis, A. (2016). Coupling of physiological and proteomic analysis to understand the ethyleneand chilling-induced kiwifruit ripening syndrome. Front. Plant Sci. 7, 120. doi: 10.3389/fpls.2016.00120

Minas, I. S., Tanou, G., Krokida, A., Karagiannis, E., Belghazi, M., Vasilakakis, M., et al. (2018). Ozone-induced inhibition of kiwifruit ripening is amplified by 1methylcyclopropene and reversed by exogenous ethylene. BMC Plant Biol. 18, 358. doi: 10.1186/s12870-018-1584-y

Molassiotis, A., Tanou, G., Filippou, P., and Fotopoulos, V. (2013). Proteomics in the fruit tree science arena: new insights into fruit defense, development, and ripening. Proteomics 13, 1871-1884. doi: 10.1002/pmic.201200428

Moreno, J. I., Martín, R., and Castresana, C. (2005). Arabidopsis SHMT1, a serine hydroxymethyltransferase that functions in the photorespiratory pathway influences resistance to biotic and abiotic stress. Plant J. 41, 451-463. doi: 10.1111/j.1365-313X.2004.02311.x

Nakaminami, K., Matsui, A., Nakagami, H., Minami, A., Nomura, Y., Tanaka, M., et al. (2014). Analysis of differential expression patterns of mRNA and protein during cold-acclimation and de-acclimation in Arabidopsis. Mol. Cell. Proteomics 13, 3602-3611. doi: 10.1074/mcp.m114.039081

Nobile, P. M. E., Wattebled, F., Quecini, V., Girardi, C. L., Lormeau, M., and Laurens, F. (2011). Identification of a novel $\alpha$-L-arabinofuranosidase gene associated with mealiness in apple. J. Exp. Bot. 62, 4309-4321. doi: 10.1093/jxb/ err146

Osuna, D., Usadel, B., Morcuende, R., Gibon, Y., Bläsing, O. E., Höhne, M., et al. (2007). Temporal responses of transcripts, enzyme activities and metabolites after adding sucrose to carbon-deprived Arabidopsis seedlings. Plant J. 49, 463-491. doi: 10.1111/j.1365-313X.2006.02979.x

Paolacci, A. R., D’Ovidio, R., Marabottini, R., Nali, C., Lorenzini, G., Abenavoli, M. R., et al. (2002). Research note: ozone induces a differential accumulation of phenyalanine ammonia-lyase, chalcone synthase and chalcone isomerase RNA transcripts in sensitive and resistant bean cultivars. Funct. Plant Biol. 28, 425. doi: 10.1071/pp00095

Roessner, U., Wagner, C., Kopka, J., Trethewey, R. N., and Willmitzer, L. (2000). Simultaneous analysis of metabolites in potato tuber by gas chromatography-mass spectrometry. Plant J. 23, 131-142. doi: 10.1046/j.1365-313X.2000.00774.x

Rowan, D. D., Allen, J. M., Fielder, S., Spicer, J. A., and Brimble, M. A. (1995). Identification of conjugated triene oxidation products of $\alpha$-farnesene in apple skin. J. Agric. Food Chem. 43, 2040-2045. doi: 10.1021/jf00056a016

Rudell, D. R., Mattheis, J. P., and Hertog, M. L. A. T. M. (2009). Metabolomic change precedes apple superficial scald symptoms. J. Agric. Food Chem. 57, 8459-8466. doi: 10.1021/jf901571g

Segonne, S. M., Bruneau, M., Celton, J. M., Gall, S., Le Francin-Allami, M., et al. (2014). Multiscale investigation of mealiness in apple: an atypical role for a pectin methylesterase during fruit maturation. BMC Plant Biol. 14, 375. doi: 10.1186/s12870-014-0375-3

Shen, Q., Chen, C. N., Brands, A., Pan, S. M., and David Ho, T. H. (2001). The stress- and abscisic acid-induced barley gene HVA22: developmental regulation and homologues in diverse organisms. Plant Mol. Biol. 45, 327340. doi: $10.1023 / \mathrm{A}: 1006460231978$

Shi, Y., Tian, S., Hou, L., Huang, X., Zhang, X., Guo, H., et al. (2012). Ethylene signaling negatively regulates freezing tolerance by repressing expression of
CBF and type-A ARR genes in Arabidopsis. Plant Cell 24, 2578-2595. doi: $10.1105 /$ tpc. 112.098640

Smyth, G. K. (2005) limma: Linear models for microarray data. In: Bioinformatics and computational biology solutions using $R$ and bioconductor. Statistics for Biology and Health. Eds. R. Gentleman, V. J. Carey, W. Huber, R. A. Irizarry and S. Dudoit, (New York, NY: Springer), 397-420. doi: 10.1007/0-387-29362-0_23

Storch, T. T., Finatto, T., Bruneau, M., Orsel-Baldwin, M., Renou, J. P., Rombaldi, C. V., et al. (2017). Contrasting transcriptional programs control postharvest development of apples (Malus x domestica Borkh.) submitted to cold storage and ethylene blockage. J. Agric. Food Chem. 65, 7813-7826. doi: 10.1021/ acs.jafc.7b01425

Tanou, G., Job, C., Belghazi, M., Molassiotis, A., Diamantidis, G., and Job, D. (2010). Proteomic signatures uncover hydrogen peroxide and nitric oxide cross-talk signaling network in citrus plants. J. Proteome Res. 9, 14, 5994-6006. doi: $10.1021 / \mathrm{pr} 100782 \mathrm{~h}$

Tanou, G., Minas, I. S., Karagiannis, E., Tsikou, D., Audebert, S., Papadopoulou, K. K., et al. (2015). The impact of sodium nitroprusside and ozone in kiwifruit ripening physiology: a combined gene and protein expression profiling approach. Ann. Bot. 116, 649-662. doi: 10.1093/aob/mcv107

Tanou, G., Minas, I. S., Scossa, F., Belghazi, M., Xanthopoulou, A., Ganopoulos, I., et al. (2017). Exploring priming responses involved in peach fruit acclimation to cold stress. Sci. Rep. 1, 14 doi: 10.1038/s41598-017-11933-3

Tsantili, E., Gapper, N. E., Apollo Arquiza, J. M. R., Whitaker, B. D., and Watkins, C. B. (2007). Ethylene and $\alpha$-farnesene metabolism in green and red skin of three apple cultivars in response to 1-methylcyclopropene (1-MCP) treatment. J. Agric. Food Chem. 55, 5267-5276. doi: 10.1021/jf0637751

Usadel, B., Nagel, A., Thimm, O., Redestig, H., Blaesing, O. E., Palacios-Rojas, N., et al. (2005). Extension of the visualization tool MapMan to allow statistical analysis of arrays, display of coresponding genes, and comparison with known responses. Plant Physiol. 138, 1195-1204. doi: 10.1104/pp.105.060459

Vergne, E., De Bernonville, T. D., Dupuis, F., Sourice, S., Cournol, R., Berthelot, P., et al. (2014). Membrane-targeted HrpNEa can modulate apple defense gene expression. Mol. Plant-Microbe Interact. 27, 125-135. doi: 10.1094/MPMI-1013-0305-R

Wang, G., Fiers, M., Ellendorff, U., Wang, Z., de Wit, P. J. G. M., Angenent, G. C., et al. (2010). The diverse roles of extracellular leucine-rich repeat-containing receptor-like proteins in plants. CRC Crit. Rev. Plant Sci. 29, 285-299. doi: $10.1080 / 07352689.2010 .502082$

Wang, L., Li, H., Zhao, C., Li, S., Kong, L., Wu, W., et al. (2017). The inhibition of protein translation mediated by AtGCN1 is essential for cold tolerance in Arabidopsis thaliana. Plant Cell Environ. 40, 56-68. doi: 10.1111/pce.12826

Wang, L., Qian, M., Wang, R., Wang, L., and Zhang, S. (2018). Characterization of the glutathione S-transferase (GST) gene family in Pyrus bretschneideri and their expression pattern upon superficial scald development. Plant Growth Regul. 86, 211-222. doi: 10.1007/s10725-018-0422-4

Zermiani, M., Zonin, E., Nonis, A., Begheldo, M., Ceccato, L., Vezzaro, A., et al. (2015). Ethylene negatively regulates transcript abundance of ROP-GAP rheostat-encoding genes and affects apoplastic reactive oxygen species homeostasis in epicarps of cold stored apple fruits. J. Exp. Bot. 66, 72557270. doi: $10.1093 /$ jxb/erv422

Zhao, W., Baldwin, E. A., Bai, J., Plotto, A., and Irey, M. (2019). Comparative analysis of the transcriptomes of the calyx abscission zone of sweet orange insights into the huanglongbing-associated fruit abscission. Hortic. Res. 6, 71. doi: 10.1038/s41438-019-0152-4

Conflict of Interest: The authors declare that the research was conducted in the absence of any commercial or financial relationships that could be construed as a potential conflict of interest.

The handling Editor declared a past collaboration with one of the authors AF.

Copyright (๑ 2020 Karagiannis, Tanou, Scossa, Samiotaki, Michailidis, Manioudaki, Laurens, Job, Fernie, Orsel and Molassiotis. This is an open-access article distributed under the terms of the Creative Commons Attribution License (CC BY). The use, distribution or reproduction in other forums is permitted, provided the original author $(s)$ and the copyright owner(s) are credited and that the original publication in this journal is cited, in accordance with accepted academic practice. No use, distribution or reproduction is permitted which does not comply with these terms. 